\title{
publiCIDADE DO BASA - BANCO DA AMAZÔNIA - COMO MARCA DE DIVULGAÇÃO DO PROGRESSO E DO DESENVOLVIMENTO DA REGIÃO
}

\author{
ADVERTISING OF BASA - BANCO DA AMAZONNIA - AS A MARK OF \\ DISCLOSURE OF THE PROGRESS AND DEVELOPMENT OF THE REGION
}

\author{
PUBLICIDAD DEL BASA - BANCO DE LA AMAZONIA - COMO MARCA DE \\ DIVULGACIÓN DEL PROGRESO Y DEL DESARROLLO DE LA REGIÓN
}

Luiz Cezar Silva dos Santos Docente Universidade Federal do Pará lzcezar@ufpa.br

\section{Resumo}

Este artigo tem por base a publiCIDADE e as mudanças históricas da construção da marca do Banco da Amazônia (BASA), por meio das mensagens publicitárias veiculadas ao longo de mais de sete décadas de existência da instituição financeira (banco). Assim, buscamos estudar a construção das marcas do banco (Banco de Crédito da Borracha, Banco de Crédito da Amazônia, BASA e Banco da Amazônia) como uma personalidade representativa do progresso e do desenvolvimento da região amazônica, como lugar de pertencimento das populações atendidas e atingidas pelos projetos financiados pelo banco estatal e suas iniciativas institucionais publicizadas com o intuito de promover, publicitariamente, o(s) discurso(s) de progresso e de desenvolvimento da Amazônia.

Palavras-chave: Marca. BASA. Banco da Amazônia. publiCIDADE.

\begin{abstract}
This article is based on the publiCITY and historical changes of the Banco da Amazônia brand building (BASA), through publicity messages transmitted over more than seven decades of existence of the financial institution (bank). Thus, we sought to study the construction of bank brands (Banco de Crédito da Borracha, Banco de Crédito da Amazônia, BASA and Banco da Amazônia) as a personality representative of the progress and development of the Amazon region as a place of belonging to the populations served and affected by the projects financed by the state bank and its institutional initiatives publicized with the purpose of promoting, publicityally, the discourse (s) of progress and development of the Amazon.
\end{abstract}

Key words: Brand. BASA. Bank of the Amazon. publiCITY. 


\section{Resumen}

Este artículo se basa en la publiCIDAD y los cambios históricos de la construcción de la marca del Banco de la Amazonia (BASA), a través de los mensajes publicitarios publicados a lo largo de más de siete décadas de existencia de la institución financiera (banco). Así, buscamos estudiar la construcción de las marcas del banco como una personalidad representativa del progreso y del desarrollo de la región amazónica, como lugar de pertenencia de las poblaciones atendidas $\mathrm{y}$, alcanzadas por los proyectos financiados por el banco estatal y sus iniciativas institucionales publicadas con el propósito de promover, publicitariamente, el (los) discurso (s) de progreso y de desarrollo de la Amazonia.

Palabras clave: Marca. BASA. Banco de la Amazonia. PubliCIDAD.

\section{INTRODUÇÃO}

É sempre um desafio o estudo da significação contida na comunicação publicitária, sobretudo pela dimensão simbólica que representa para uma marca em determinada época e local.

Esse é o caso das publicidades do Banco da Amazônia, que, ao longo de seus 75 anos de existência, sofreu alterações que buscaram pontuar, nas diferentes situações históricas vividas, o desenvolvimento da região amazônica. Essa trajetória parece evidenciar o lugar de pertencimento da marca e sua relação com o progresso e o crescimento dessa região do país.

Nessa direção, apresenta-se a trajetória do banco, desde sua criação em 1942 até os dias atuais, incluindo as diferentes denominações que o banco recebeu ao longo dos anos. Em seguida, destacam-se algumas peças publicitárias, para mostrar as articulações de sentido nelas presentes (nas denominações que recebeu de Banco de Crédito da Borracha, Banco de Crédito da Amazônia, BASA e Banco da Amazônia), que evidencia a estreita relação entre a instituição financeira e o desenvolvimento da região amazônica a ela associada.

\section{CRONOLOGIA DA MARCA DO BANCO DA AMAZÔNIA}

1942 - ressurge das cinzas, na região amazônica, um sopro de esperança com a volta do comércio do látex, relembrando o período de 1870 a 1912, também conhecido como época áurea do Ciclo da Borracha, já que "não havia outro lugar para ir buscar o produto, fora da Amazônia brasileira, que fora, no início do século, a maior área produtora do mundo.” (DA SILVA, 2002: 404).

Ao final da segunda metade do século XIX, Belém já comandava os negócios da região em relação às riquezas produzidas pelo comércio da 
borracha, e essa riqueza já se fazia presente nas mudanças urbanísticas, preparando a cidade para ser a capital da borracha na Amazônia, no Brasil e no mundo. (SANTOS, 2010: 30).

Mesmo que historicamente, entre os anos de 1912 e 1942, houvesse uma desaceleração da produção de borracha na região, principalmente em função da disputa de mercado com os países do Oriente (Ceilão, Índia, Malásia, Birmânia e Indonésia), grandes produtoras mundiais de látex, a era da borracha é sempre vista como um momento de enorme euforia econômica, política e cultural na região. A criação do Banco da Borracha (Figura 1), pelo Decreto Lei $\mathrm{n}^{\mathrm{o}}$ 4.451, de 9 de julho de 1942, em decorrência dos acordos de Washington assinados entre o Brasil, governado por Getúlio Vargas, e os Estados Unidos da América, governado por Franklin Delano Roosevelt, com a finalidade de produção de borracha (látex) para auxiliar no esforço de guerra (II Grande Guerra Mundial) consolidando o sistema de financiamento da exploração do látex na Amazônia como um dos produtos requisitados pela economia fomentada pela guerra.

A borracha, que sempre foi importante na economia regional, torna-se, com a eclosão da Segunda Guerra Mundial, matéria-prima altamente estratégica para as forças aliadas, uma vez que os seringais do Oriente haviam caído nas mãos dos japoneses. (DA SILVA, 2002: 404).

O novo ciclo da borracha instituído, diferentemente do "sonhado" pelos proprietários de seringais e pelos governos locais, constitui, segundo Amaral Filho (2016), “o exemplo mais significativo desse modo capitalista de exploração com base no crescimento econômico como forma de desenvolvimento." (AMARAL FILHO, 2016: 90). Em outras palavras, o desenvolvimento como atividade trazida para a região no modelo das economias externas, calcado na exploração de recursos naturais, com o uso de mão de obra barata, de base colonial, expoliativa e exportadora, deixou na região, como herança, uma população degradada que precisou refazer sua vida de forma contínua, usando a floresta viva como riqueza.

Olhar para essa economia do desenvolvimento como crescimento econômico significa, antes de tudo, atentar para o seu modelo de financiamento e, entre eles, talvez o mais representativo tenha sido a criação de um banco na Amazônia: o Banco de Crédito da Borracha. Por esse nome sugestivo, foi estabelecida a primeira referência marcária da região, com a propagação do significado econômico da borracha. (Figura 1) 


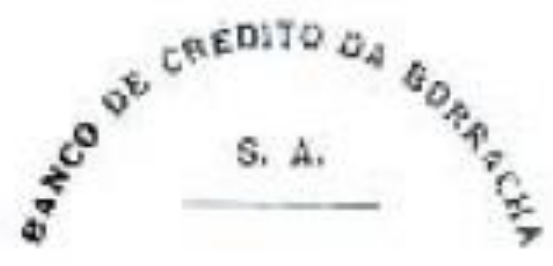

Figura 1: Banco de Crédito da Borracha.

Fonte: www.bancoamazonia.com.br/images/arquivos/biblioteca/livro_70anos/Livro_70_anos_WEB.pdf

Posteriormente, mudaria de nome ao trocar o termo "Borracha" por "Amazônia", conforme apresentado no Relatório BCB, Banco de Crédito da Borracha S.A., publicado em 1949.

Hoje este Banco nada tem a justificar o seu título. Fundado exclusivamente para fomentar e assistir à produção da borracha, teve seu campo de ação ampliado. [...] Deixou de ser o Banco da Borracha para ser, na realidade, um grande Banco de crédito geral. Impõe-se, pois, a substituição de seu nome, e, nenhum mais apropriado que o indicado pela III Conferência Nacional da Borracha: BANCO DE CRÉDITO DA AMAZÔNIA S.A. (BASTOS, 2012: 93).

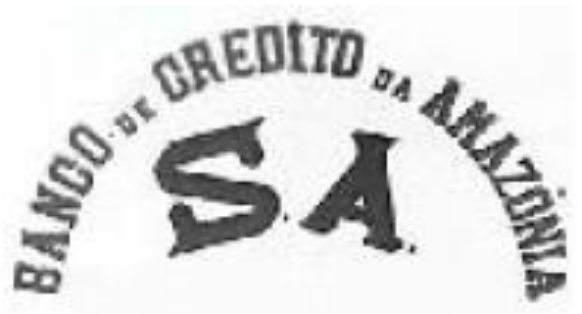

Figura 2: Banco de Crédito da Amazônia.

Fonte: www.bancoamazonia.com.br/images/arquivos/biblioteca/livro_70anos/Livro_70_anos_WEB.pdf

Na nova denominação (Figura 2), aparece o nome da região como referência marcaria para a criação do nome do banco, ou seja:

A "Amazônia" se constitui, portanto, como uma marca a partir de uma proposta de valor que, por sua natureza polissêmica, parece conferir aos vários produtos e serviços que agregam este nome, uma valoração garantida pelo nível de publicização que a palavra atingiu. (AMARAL FILHO, 2016: 58).

E mais ainda, a marca Amazônia vai gerar novos e velhos discursos sobre a região, ou nas palavras de Amaral Filho:

A imagem da Amazônia, como uma marca, é constituída a partir de estereótipos genéricos como floresta, rios, bichos, índios que estão no imaginário universal e que se juntam a outros de um imaginário popular 
representado no imaginário mítico como o Boto, a Boiuna, a Iara. Acrescente-se a estes outros conceitos trazidos pelos viajantes como inferno verde, pulmão do mundo, celeiro do mundo, que amplia e se refina possibilitando à publicidade oferecer para a Amazônia outros conceitos ainda, estes trazidos do conhecimento científico, como um inventário simplificado da ciência, em que se apresentam a biodiversidade, o manejo florestal e o desenvolvimento sustentável, entre tantos outros, oriundos do discurso científico. (AMARAL FILHO, 2016: 41/42).

O discurso de desenvolvimento e progresso está presente não somente na(s) marca(s), mas também nas mensagens dos anúncios publicitários do Banco, como iremos ver mais adiante. Conforme Corrêa (2002), durante a década de 1950 e o início dos anos 1960, segundo relatório da Consultoria BRASTEC (Sociedade Brasileira de Serviços Técnicos e Econômicos LTDA), encomendado pelo BCA, a infraestrutura econômica e social na região era "inadequada, obsoleta, insuficiente e antieconômica, quer se tratasse de transporte, energia elétrica, saúde pública, abastecimento de água, rede de esgoto ou serviço bancário". (CORRÊA, 2002: 358).

Além disso, na década de 1950, o Brasil atravessava uma onda nacionalista, ou seja, "Vivíamos os dias do nacional-desenvolvimentismo e acreditava-se na importância do papel econômico do Estado, na luta pelo desenvolvimento". (DA SILVA, 2002: 411). Da Silva também faz menção ao Relatório do BCA do exercício de 1962, que afirma: "É importante, imprescindível mesmo, se quisermos pensar em termos de desenvolvimento econômico, que tal assistência atinja realmente aos legítimos produtores, àqueles cujo trabalho, na conjuntura atual, pouco proveito lhe traz, enriquecendo apenas aos donos da produção, os que lhes proporcionam apenas o indispensável a continuarem vivos, a seguirem no seu papel de máquinas produtoras da riqueza alheia”. (DA SILVA, 2002: 415).

Esse panorama também refletia as ações governamentais do período que trabalhava mais em detrimento do capital comercial da região do que em favor do desenvolvimento regional. Segundo Corrêa (2002: 360), "Essa era a performance da economia amazônica, às vésperas das grandes transformações que chegariam com a década de 1970. Uma produção modesta atendia o restrito mercado interno, e contava como o apoio do BCA na geração de algum excedente para exportação".

Atividades como a pesca artesanal, bovinocultura extensiva, lavouras de subsistência (arroz, milho e mandioca), culturas comerciais (pimenta-doreino, juta e malva), diamantes, peles e couros silvestres, produtos extrativistas (castanha, borracha, balata, sorva, ucuquirana), além de algumas pequenas indústrias localizadas nos principais centros urbanos, como fumo, 
sabão, perfumes, refrigerantes, calçados, curtição de couro, madeira - eram exemplos dos negócios de pequena escala característicos da economia regional. (CORRÊA, 2002: 361).

A descrição acima sobre a economia regional demonstra que o BCA - Banco de Crédito da Amazônia estava direcionado para investir nos grandes negócios, em detrimento dos pequenos produtores. Nesse contexto econômico e político permeado pelos interesses do capital nacional e multinacional, "a Amazônia deixaria de ser considerada mera fornecedora de produtos extrativos, para assumir o papel de fronteira econômica para reprodução do capital" (CORRÊA, 2002: 363). Para apoiar todo esse complexo sistema político e econômico, foi criada a Superintendência do Desenvolvimento da Amazônia - SUDAM, a Superintendência da Zona Franca de Manaus - SUFRAMA e, posteriormente, foi lançado o Programa de Integração Nacional - PIN.

Em 1966, já sob o regime dos governos militares, o banco foi rebatizado de Banco de Crédito da Amazônia para Banco da Amazônia S.A., e passou a ser conhecido popularmente pela sigla BASA (Figura 3), e "torna-se o agente financeiro do governo federal para o desenvolvimento econômico e social da região. O cadeado da logomarca significava segurança e tradição.” (BASTOS, 2012: 155).

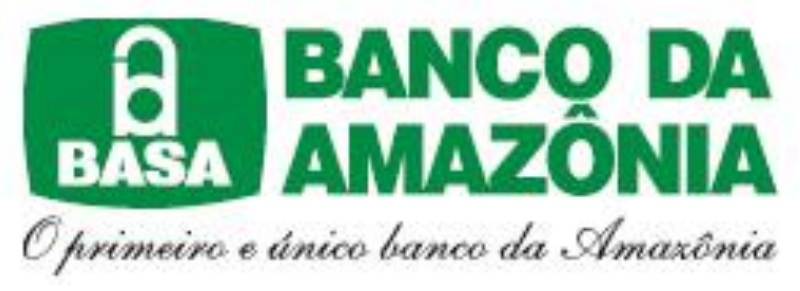

Figura 3: BASA - Banco da Amazônia.

Fonte: www.bancoamazonia.com.br/images/arquivos/biblioteca/livro_70anos/Livro_70_anos_WEB.pdf

A marca do BASA é formada por um logotipo composto pelo nome Banco da Amazônia, representado por uma fonte tipográfica que a distingue das outras marcas de banco, além do uso de um artificio visual: o cadeado, símbolo que remete à segurança, à guarda de algo, ao fechamento seguro de alguma coisa.

O significado principal de uma marca é o resumo das principais associações feitas pelo consumidor e das percepções dominantes sobre ela, uma fotografia instantânea que imediatamente vem à mente ao se ouvir o nome da marca. Simplesmente, é a maneira pela qual o consumidor define certa marca espontaneamente. (BARTEY, 2010: 210). 
Para Corrêa, a região é "vista como fronteira para expansão do capital, o dinamismo da Amazônia, em toda a sua história", ainda segundo o autor, "é marcado por três componentes externos: a ação do Estado, a demanda de recursos naturais e o excedente de população do resto do País." (CORRÊA, 2002: 385). Portanto, “A preocupação do BASA com a situação socioeconômica da população interiorana da Região foi uma constante, desde a sua criação”. (DA SILVA, 2002: 414). Com essa finalidade, o BASA, no período de 1971 a 1975, procurou dotar de vantagens competitivas os setores de mineração, madeira e turismo indicando-os como indústrias estratégicas para competir nos mercados nacional e internacional. Mesmo assim, no referido período, do ponto de vista do desenvolvimento, a região amazônica deixava muito a desejar com relação aos indicadores macroeconômicos.

\section{DETALHAMENTO DOS ANÚNCIOS SELECIONADOS}

Com o título "De onde viemos e para onde vamos", o anúncio comemorativo dos 30 anos de existência do BASA (Figura 4), publicado em 1972, traz em sua mensagem referências a diversos pontos já citados anteriormente, principalmente, a "importância" do banco para o desenvolvimento da região amazônica.

\section{De onde viemos e para onde vamos.}
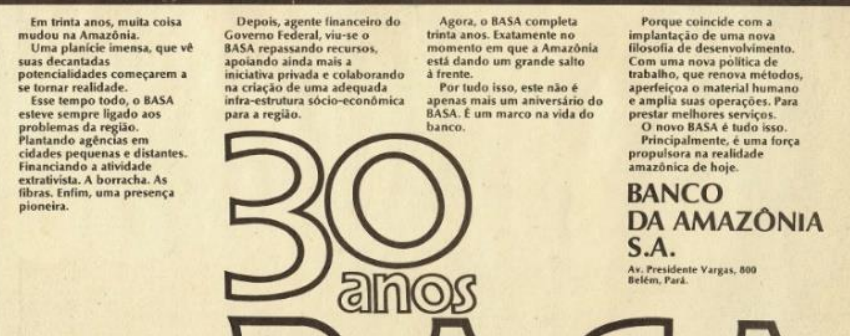

DA.A.

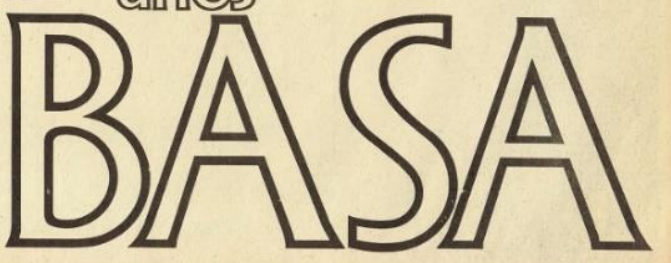

Figura 4: Anúncio dos 30 anos BASA.

Fonte: Jornal O Liberal, publicado dia 09 de julho de 1972.

Segue abaixo o texto do anúncio:

Em trinta anos, muita coisa mudou na Amazônia. 
Uma planície imensa, que vê suas decantadas potencialidades começarem a se tornar realidade.

Esse tempo todo, o BASA esteve sempre ligado aos problemas da região.

Plantando agências em cidades pequenas e distantes. Financiando a atividade extrativista. A borracha. As obras. Enfim, uma presença pioneira.

Depois, agente financeiro do Governo Federal, viu-se o BASA repassando recursos, apoiando ainda mais a iniciativa privada e colaborando na criação de uma adequada infra-estrutura sócio-econômica para a região.

Agora, o BASA completa trinta anos. Exatamente no momento em que a Amazônia está dando um grande salto à frente.

Por tudo isso, este não é apenas mais um aniversário do BASA. É um marco na vida do banco.

Porque coincide com a implantação de uma nova filosofia de desenvolvimento. Com uma nova política de trabalho, que renova métodos, aperfeiçoa o material humano e amplia suas operações. Para prestar melhores serviços.

O novo BASA é tudo isso.

Principalmente, é uma força propulsora da realidade amazônica de hoje.

Contudo, apesar da mensagem publicitária incentivadora, a Amazônia, segundo Da Silva (2002), está longe de ver equacionados os seus problemas básicos. "Sua indiscutível potencialidade de riquezas minerais e vegetais, que sempre despertou a cobiça internacional, ainda aguarda recursos e decisão para o seu aproveitamento.” (DA SILVA, 2002: 417/18).

No final da década de 80 e no início da de 90, era preciso reformular o conceito de desenvolvimento regional e seus instrumentos econômicos. Assim, criticada por sua dimensão exclusivamente quantitativa, segundo Corrêa (2002), "a noção de desenvolvimento regional passava agora a incorporar, em meio a essa atmosfera de democratização da vida brasileira, a dimensão qualitativa", ou seja, para o autor, passava "de forma dominante, interiorizando a noção de sustentabilidade expressa na busca da harmonia entre os objetivos econômicos, sociais e ambientais". (CORRÊA, 2002: 383).

Buscando se fazer presente fisicamente em cada Estado da Amazônia, o Banco da Amazônia - BASA, a mais de uma década, vem estabelecendo parcerias específicas com os setores público e privado e seus diversos atores sociais, sensibilizando a todos, "quanto à necessidade de agirem articuladamente nas questões atinentes ao desenvolvimento", questões que envolvem desde "a infraestrutura socioeconômica, até a constituição de políticas de ciência e tecnologia, fundiária, agroflorestal, mineração, preservação ambiental, entre outras" (CORRÊA, 2002: 388).

Nas comemorações dos 50 anos do BASA, em 9 de julho de 1992, não foi publicado nenhum anúncio alusivo à data comemorativa, apenas outras instituições fizeram anúncios homenageando-o pela data, como o da FIEPA/CIP, criado pela Griffo Comunicação, com o simbólico título: "BASA. 50 
ANOS DE UM SÍMBOLO DO DESENVOLVIMENTO AMAZÔNICO”. Um símbolo histórico reforçado no texto do anúncio: “A história do Basa está para sempre ligada a gerações de empresas e empresários, que enfrentaram juntos o desafio amazônico.” E conclui: "Basa, hoje, não é apenas uma sigla. É um símbolo."

Para Amaral Filho (2016):

Houve um incentivo de órgãos financiadores como o Banco da Amazônia, por exemplo, estimulando o extrativismo ou contribuindo para o desaparecimento através dos plantios racionais, como o do guaraná e da criação de novas alternativas econômicas para a região como a do cupuaçu, a da pupunha e principalmente a do açaí. (AMARAL FILHO, 2016: 62).

O conjunto de ações tratado como desenvolvimento, seja sustentável, seja de biodiversidade, na verdade, vai se caracterizar, principalmente, pela exploração dos recursos propiciados pela floresta, pelos rios, acrescidos da exploração e da espoliação das populações locais, mas, nos discursos do marketing e da publicidade e propaganda, ganha a denominação de "comércio justo".

Em 2002, ao completar 60 anos, a marca do Banco passa por outra reformulação: saem a sigla BASA e o cadeado e enfatiza-se o nome Banco da Amazônia escrito por extenso, ou seja, a marca enfatiza a palavra "Amazônia". A nova marca (Figura 5) traz o 'A' maiúsculo representando solidez; e a 'onda amarela', desenvolvimento. Conceitualmente, o uso da cor amarela, mais que representar o metal precioso (o ouro), como indicativo para lembrar que a Amazônia também faz parte do Brasil, ou seja, pertence à Nação brasileira. A nova marca do Banco trabalha a letra "A" em caixa alta, entrelaçada por símbolo que remete a uma folha ou a um rio que corta a letra dando sentido de caminho. De certa forma, a cor verde funciona como uma denominação também da floresta. Segundo Amaral Filho (2016), "como se busca representar a Amazônia pela floresta, a cor termina por se constituir em um elemento para esta percepção a que estamos nos referindo. Árvore, folha, dégradé do verde, são elementos dessas composições.” (AMARAL FILHO, 2016: 197). Por fim, “o conceito de marca deve encontrar uma expressão, ou pelo menos estar refletido, na comunicação da marca, no nome, no slogan e nos outros elementos de marketing.” (BARTEY, 2010: 269). Com a nova marca, o Banco assume, ainda, segundo Bastos (2012), "sua responsabilidade socioambiental e passa a priorizar o repasse de créditos baseados no desenvolvimento sustentável, apoiando ações culturais, sociais, esportivas e de pesquisa.” (BASTOS, 2012: $155)$. 


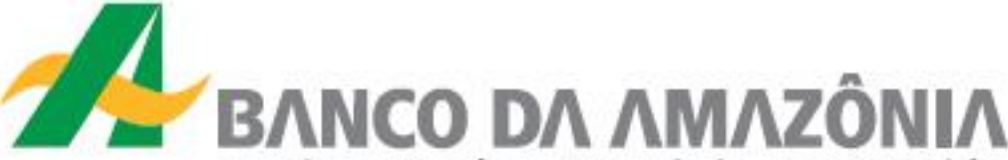 Movimentando a Amazônia. E a sua vida.}

Figura 5: Banco da Amazônia.

Fonte: www.bancoamazonia.com.br/images/arquivos/biblioteca/livro_70anos/Livro_70_anos_WEB.pdf

Segundo Bartey (2010), "um produto físico se torna uma marca quando é acrescido de algo mais - imagens, símbolos, percepções, sentimentos - para produzir uma ideia total maior do que a soma de suas partes. (BARTEY, 2010: 27). O que dizer, então, do produto físico "Amazônia". Uma região geográfica localizada no Norte do Brasil e cortada pela linha do Equador, acrescente-lhe uma floresta, um grande rio e outros mais, uma fauna e uma flora diversificada, e temos a "marca Amazônia". Uma marca midiática, conforme nos diz Amaral Filho:

A Marca Amazônia está na mídia como um discurso cultural, econômico, ecológico e científico, mas o que nos interessa aqui é defini-la como um elemento do sistema de signos da publicidade, logo, como uma proposição ideológica que envolve nomeações, conceitos e imagens com a finalidade precípua de persuadir e seduzir para a compra da mercadoria. (AMARAL FILHO, 2016: 58/59).

Para os consumidores, a quem são dirigidos todos os interesses e a quem são atribuídos os melhores resultados, a marca Amazônia também é fruto de uma série de percepções, de associações que povoam em suas cabeças, incluindo aí todo o universo imaginário criado e propagado pelas mídias sobre a Amazônia. Por isso mesmo, a Amazônia como Marca, nas palavras de Amaral Filho (2016), "parece se constituir em uma matriz cultural produzida pela midiatização e por uma narrativa baseada em dados fantásticos e reais", matrizes que, segundo o autor, "tiveram origem em universos simbólicos locais que foram apropriados e ofertados com um sentido dado pela publicidade para o mercado global." (AMARAL FILHO, 2016: 114).

No anúncio comemorativo dos 70 anos do Banco da Amazônia (Figura 6), publicado em julho de 2012, a mensagem publicitária faz referências à história do Banco para o desenvolvimento da região amazônica. Com o título: "BANCO DA AMAZÔNIA 70 ANOS. UMA HISTÓRIA EM MOVIMENTO.” E o texto do anúncio afirma:

Cresci com um compromisso: desenvolver de forma sustentável uma grande região. 
Desafiei o sol, os rios, as distâncias. Ganhei respeito, amigos. Caminhei de mãos dadas com a esperança.

Acredito no trabalho ético, na tecnologia ao alcance de todos, nas fontes de energia limpa, no empreendedorismo consciente, no movimento pela geração de emprego e renda para o povo da floresta.

Meu verdadeiro lucro é melhorar a vida das pessoas. Eu sou a história, sou o futuro, sou você, sou a Amazônia.
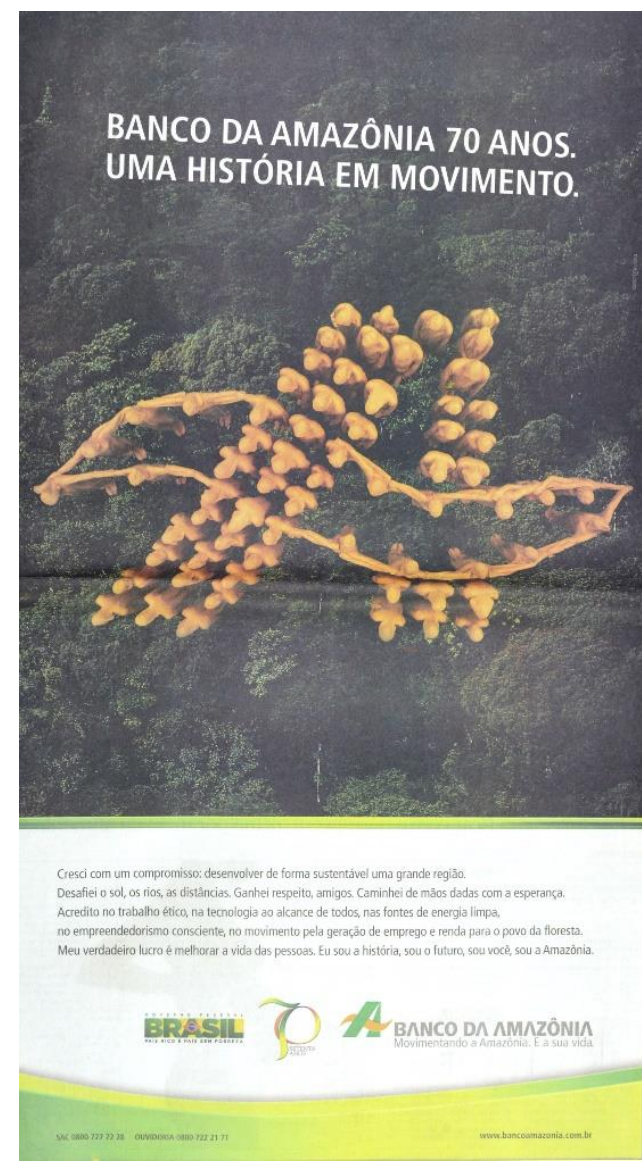

Figura 6: Anúncio dos 70 anos BASA.

Fonte: Jornal O Liberal, publicado dia 09 de julho de 2012.

$\mathrm{Na}$ assinatura do anúncio, abaixo da logomarca do Banco, aparece o slogan: "Movimentando a Amazônia. E a sua vida".

A publicidade, por sua vez, segundo Amaral Filho (2016), "usa a simulação para criar a sensação do testemunhal e da comprovação como elementos fundadores da sua fala" e, ainda, "um mundo publicitário, cuja matriz criada pelo consumo, oferece sociabilidades que redefinem o comportamento e o estilo de vida" (AMARAL FILHO, 2016: 33). A proposta comercial da peça publicitária comemorativa aos 70 anos do Banco busca evidenciar, por meio de um depoimento histórico-testemunhal, a importância da instituição financeira, Banco da Amazônia, para a região. 
Para Amaral Filho (2016: 166):

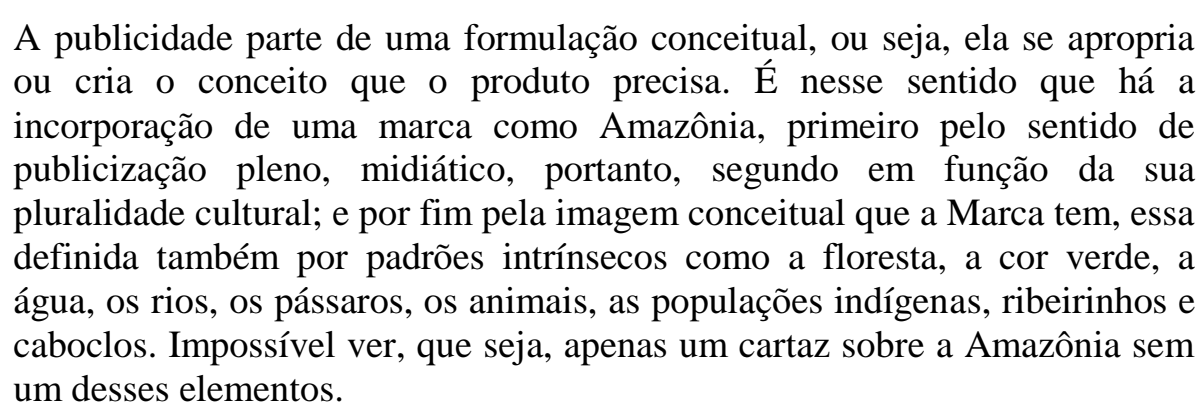

Como se viu, essa apropriação conceitual do produto, do serviço e da marca precisa se fazer presente nas peças publicitárias criadas e produzidas para divulgar as datas comemorativas do Banco da Amazônia, órgão financeiro criado para e pela própria região. A peça publicitária abaixo (Figura 7), por sua vez, é um exemplo dessa presença do banco e de sua marca nas cidades da região.

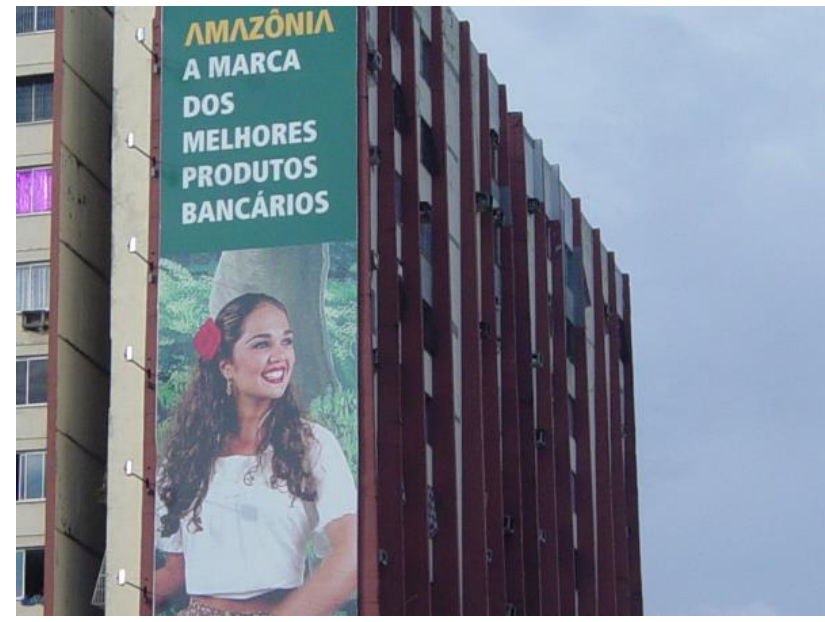

Figura 7: Empena do Banco da Amazônia na cidade de Belém do Pará - 2007. Fonte: Fotografia de Otacílio Amaral Filho

\section{CONSIDERAÇÕES}

Tendo por base as mudanças históricas da construção da marca BASA, posteriormente denominada Banco da Amazônia, por meio das mensagens publicitárias veiculadas ao longo de mais de sete décadas de existência da instituição financeira (banco), buscou-se mostrar a efetividade e a robustez da marca de uma empresa, no caso do Banco da Amazônia, que associa valor conceitual e ativo simbólico, para representar a sua atividade fim, ou seja, o financiamento bancário na região amazônica ao longo desse tempo. Do Banco de Crédito da Borracha ao Banco de Crédito da Amazônia, passando pelo BASA e chegando ao Banco da 
Amazônia, ficam reiteradas duas características publicitárias dominantes da marca: o nome Amazônia e a cor verde como um signo da floresta.

A marca Amazônia apresenta de modo geral cinco atributos relacionados a fauna e a flora, principalmente, a floresta, quando associados a produtos originários da região ou que sugerem ao consumidor terem sidos produzidos na região, a saber: original, natural, seguro, saudável e sustentável. As marcas com o tempo, segundo Bartey (2010), “constroem um vocabulário próprio - palavras que são associadas àquela marca não só no slogan, mas também nas descrições que são feitas do produto e na propaganda impressa ou on-line, por exemplo.”(BARTEY, 2010: 64). O que dizer então da marca Amazônia, um nome/marca utilizado mundo afora nos mais diversos ramos comerciais, como as marcas: Amazon.com, AMA4ONIA: moda ecológica, Amazon Beer, Cerveja puro malte Amazônia, AmazôniaUP Empreendedorismo Sustentável, Amazon Art, Amazônia Sistemas, Amazônia Mix Açaiteria, Amazônia Viva Cosméticos, Amazônia Fishing Lodge, Amazônia Industria e Comércio Ltda., o chá Amazônia com coco + mate com limão, os cosméticos da Chamma da Amazônia, Amazônia Moda masculina, Amazônia Reality Show, Peixes da Amazônia, Pirarucu da Amazônia, Tacacaria Amazônia, Sabor da Amazônia Fast e Food, Bombons Finos da Amazônia, Ecomuseu da Amazônia, Fundo Amazônia, Unama - Universidade da Amazônia, FIBRA - Faculdade Integrada Brasil Amazônia, o jornal Diário da Amazônia, RBA - Rede Brasil Amazônia de Comunicação, Amazônia Marcas \& Patentes, dentre outras marcas nacionais e internacionais.

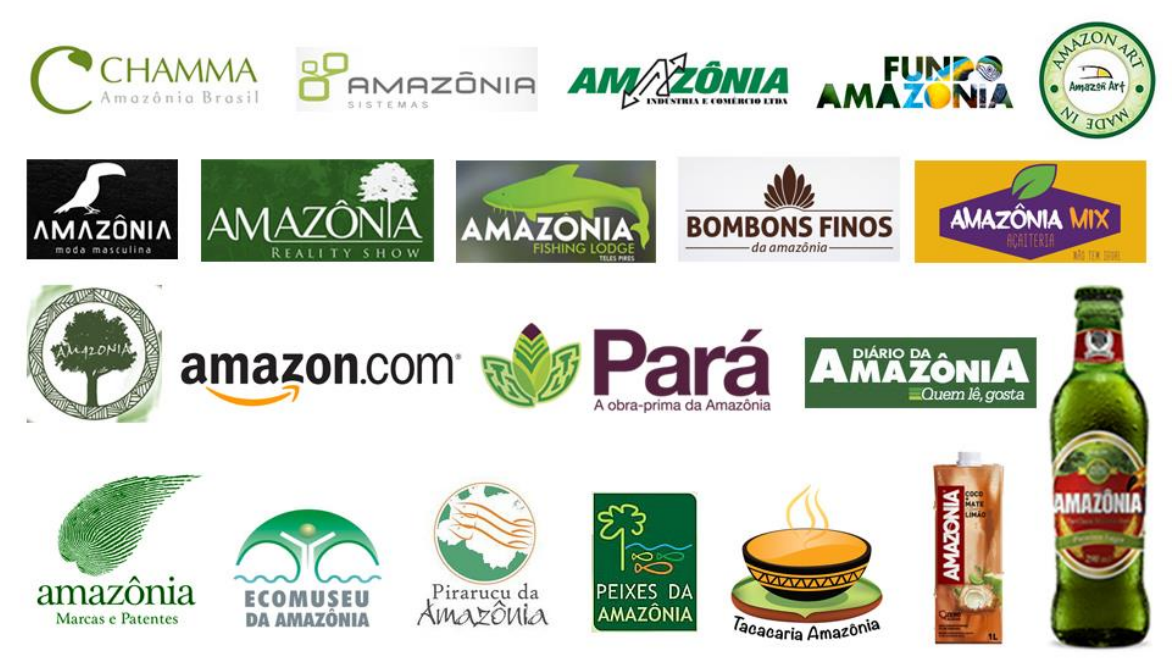

Figura 8: Marcas Amazônia

Fonte: Montagem do autor 
Contudo, o presente artigo tem por base o estudo da construção da marca BASA como uma personalidade representativa do progresso e do desenvolvimento da região amazônica, tanto para o Brasil quanto para o mundo. Bem como, a publiCIDADE do Banco da Amazônia (BASA), cidade-região sede do banco, como lugar de pertencimento das populações atendidas e atingidas pelos projetos financiados pelo banco estatal e suas iniciativas institucionais publicizadas com o intuito de promover publicitariamente o(s) discurso(s) de progresso e de desenvolvimento da Amazônia.

Na região amazônica, as formas de ocupação constituídas principalmente por
áreas de fronteira, como é o caso da expansão pecuária, agronegócio e
mineração, é que exercem uma pressão de forma direta na migração interna
nacional como fator de crescimento demográfico principalmente das
populações urbanas.[...]Esta pressão sobre os mercados vai afetar tendências
econômicas, especialmente aquelas ligadas ao poder aquisitivo que por sua
vez, estão ordenadas por fatores como a renda normal, a poupança, os preços
e disponibilidade de crédito. [...] então é preciso olhar os fatores econômicos
que movimentam estas populações como poder aquisitivo que são
importantes para o atendimento de necessidades dos consumidores...
(AMARAL FILHO, 2016: 74).

Trata-se de um estudo do uso da criação e da comunicação da marca do Banco da Amazônia, por meio de anúncios publicitários impressos veiculados nos jornais. Desde os tempos do "BASA" que o banco é publicizado como ferramenta de marketing para a divulgação midiática da marca do Banco da Amazônia, dentro e fora da região amazônica, ou seja, no território nacional. Não é à toa que o Banco propagandeia nas peças publicitárias comemorativas dos seus 75 anos, comemorados em julho de 2017, o mote: "Investindo em pessoas, desenvolvendo a Amazônia sustentável".

O nome e a marca do Banco da Amazônia passaram por algumas mudanças ao longo dos anos. Segundo Bastos, "Mudanças que procuravam retratar o contexto histórico e de política econômica do governo federal em cada época na região.” (BASTOS, 2012: 154). Sendo assim, as marcas utilizadas pelo banco, desde a sua criação (Banco de Crédito da Borracha, Banco de Crédito da Amazônia, BASA e Banco da Amazônia), trazem consigo inúmeros simbolismos que nos remetem ao patrimônio marcário da região como forma de representação cultural, social, econômica e política dos símbolos e das características peculiares da floresta, dos rios, da fauna, da gente e das cidades urbanas e rurais da Amazônia. 


\section{REFERÊNCIAS}

AMARAL FILHO, Otacílio. Marca Amazônia: o marketing da floresta. Curitiba, PR: CRV, 2016.

BARTEY, Mark. O significado da marca: Como as marcas ganham vida na mente dos consumidores. Rio de Janeiro: Best Business, 2010.

BASTOS, Luiza (et ali). Banco da Amazônia 70 anos. Belém: PLW Projetos e Linguagens; Banco da Amazônia, 2012.

CORRÊA, Roberto Ribeiro. Basa: seis décadas de mudança institucional. In A Amazônia e o seu banco. In: MENDES, Armando Dias (Org.). Manaus: Editora Valer/ Banco da Amazônia, 2002.

DA SILVA, Luiz Osíris. Três capítulos importantes da história do Basa. In A Amazônia e o seu banco. In: MENDES, Armando Dias (Org.). Manaus: Editora Valer/ Banco da Amazônia, 2002.

SANTOS, Luiz LZ Cezar Silva dos. publicidade na Belém da belle époque entre os anos de 1870 e 1912. Curitiba: Appris, 2018.

Original recebido em: 04 de janeiro de 2018

Aceito para publicação em: 04 de junho de 2019

Luiz Cezar Silva dos Santos

Pós-Doutor em Comunicação e Consumo pelo PPGCOM/ECA/USP. Doutor em História pela PUC/SP. Mestre em Estudos Literários pela UFMG. Graduado em Comunicação Social - Publicidade e Propaganda - pela UFPA. Docente do curso de Publicidade e Propaganda - Facom/ILC/UFPA e do Programa de Pós-Graduação em Comunicação, Cultura e Amazônia - PPGCom/ILC/UFPA. Diretor Norte da Associação Brasileira de Pesquisadores em Publicidade - ABP2.

\section{(2) $(\Theta \Theta$}

Esta obra está licenciado com uma Licença

Creative Commons Atribuição-NãoComercial-CompartilhaIgual 4.0 Internacional 